Article

\title{
Traffic Safety at Median Ditches: Steel vs. Concrete Barrier Performance Comparison Using Computer Simulation
}

\author{
Ayhan Öner Yücel ${ }^{1}$ (D), Ali Osman Atahan ${ }^{2, * \mathbb{C}}$, Turan Arslan ${ }^{3}$ and Umur Korkut Sevim ${ }^{4}$ \\ 1 Department of Civil Engineering, Middle East Technical University, 06800 Ankara, Turkey; \\ ayucel@metu.edu.tr \\ 2 Department of Civil Engineering, Istanbul Technical University, 34469 Istanbul, Turkey \\ 3 Department of Civil Engineering, Bursa Uludag University, 16059 Bursa, Turkey; tarslan@uludag.edu.tr \\ 4 Department of Civil Engineering, Iskenderun Technical University, 31200 Hatay, Turkey; \\ ukorkut.sevim@iste.edu.tr \\ * Correspondence: atahana@itu.edu.tr
}

Received: 22 August 2018; Accepted: 25 October 2018; Published: 1 November 2018

check for updates

\begin{abstract}
In Turkey, concrete V-shaped ditches are formed at the median section of divided highways to provide drainage. Recent accidents show that these ditches actually present safety risks to vehicles entering the medians. Vehicles either cross over the ditch, roll over, or become trapped in the ditch, depending upon the mass, size, speed, and angle of the entering vehicle. To overcome this safety risk and reduce the severity of these accidents, longitudinal barriers are installed along these ditches. Currently, in Turkey, steel barriers are extensively used to improve traffic safety at median ditches. In this paper, the crash performances of steel and concrete barriers used at medians with ditches are compared. A model of a standard steel EDSP-1.33 barrier and a model of a newly developed concrete C470 barrier were constructed, and impact simulations were performed for when they are installed at a ditch slope break point. A nonlinear finite element program, LS-DYNA, was used for the analysis. A 13,000 kg bus model was used to impact both barriers in accordance with European standard requirements for crash tests. Simulation results show that when the steel EDSP-1.33 barrier is used, the bus has the potential for excessive penetration of the ditch, with significant barrier deformation. Moreover, the barrier damage is extensive, resulting in increased maintenance costs. On the other hand, the concrete C470 barrier successfully contains and redirects the 13,000 kg bus impact, with minimal barrier deformation and safety risk. Even though the concrete barrier slides toward the inside of the ditch, the bus does not enter the ditch area and exits the barrier in a stable manner. Therefore, to increase traffic safety at ditches located at the median section of divided highways in Turkey, utilization of the newly developed concrete barrier C470 is recommended.
\end{abstract}

Keywords: ditch; traffic safety; simulation; concrete barrier; steel barrier; LS-DYNA; divided highway

\section{Introduction}

In recent years, the General Directorate of Highways (KGM) of Turkey has initiated a major highway rehabilitation program involving the upgrading of existing single-platform roads to become divided into two or more lane roads separated by a median. A V-shaped ditch with a triangular cross-section was designed and constructed along the roads, as shown in Figure 1. These concrete median ditches are intended to provide rainwater drainage. Although drainage is essential to any roadway project, this particular design represents a potential safety hazard to drivers that lose control and encroach on the median in an uncontrolled manner. 


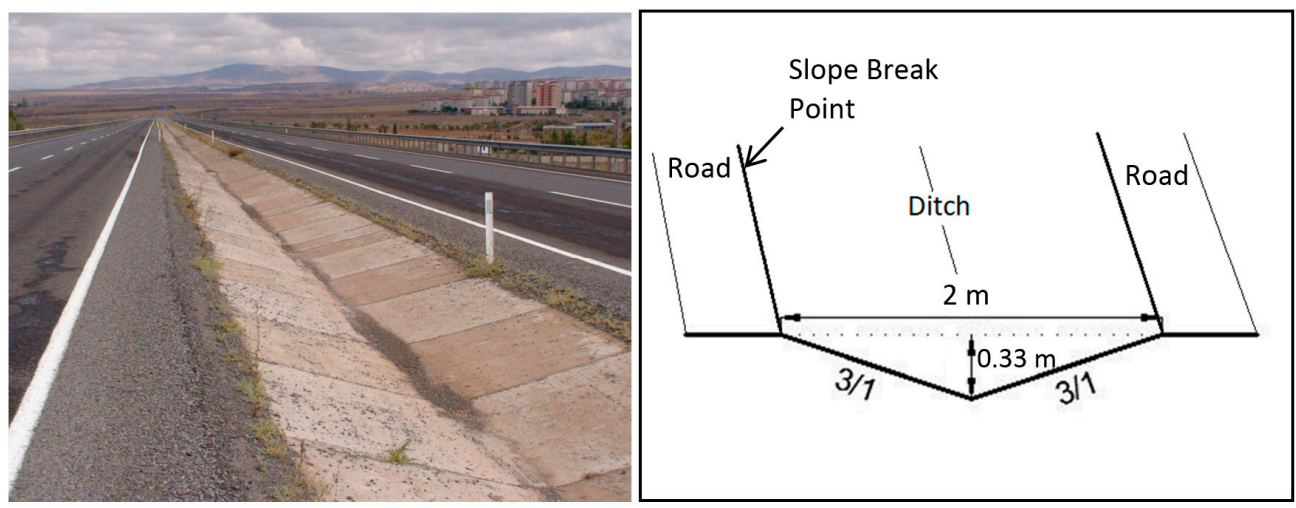

Figure 1. V-shaped ditch constructed at the median of divided highways in Turkey.

In addition, when a vehicle leaves a divided highway and crosses the median, the risk of a high-speed head-on collision with a vehicle in the opposing traffic becomes imminent [1]. To prevent or reduce vehicles' crossing over the median, road restraint systems (RRSs) are usually utilized [2]. However, it should be noted that although the existence of median restraint systems can greatly reduce median crossover accidents, it increases the frequency of less severe median barrier crashes $[1,3,4]$. Martin et al. conducted a study to assess the influence of longitudinal barriers located at medians on crash severity. The study was based on the data recorded from 1996 to 2010 on a French toll motorway. They concluded that concrete barriers are much more effective at preventing the complete median crossing of heavy vehicles. When a narrow working width is required, the use of concrete barriers is inevitable [5].

Previous research suggests that the type of road restraint system and its placement play essential roles in the acceptable performance of these designs during an impact [6,7]. Therefore, it becomes critical to contain and redirect vehicles from entering the ditches in such cases. As a result, using barriers on both sides of the median becomes critical.

A longitudinal barrier that is eligible for use on highways should meet the criteria defined by European standard of EN 1317 for crash tests [8]. In this standard, crash tests are performed with standard vehicle sizes, with controlled speed and impact angles. Usually, barriers are installed on flat surfaces. Some exceptional tests have been performed on sloped surfaces. Therefore, the behavior of vehicles on graded surfaces, such as ditches, is not well known. Furthermore, and most importantly, in the majority of guardrail applications in Turkey, due to restrictions in road space, guardrails are installed inside or very close to the ditch slope break point [9]. Hence, the wheels of vehicles that contact the guardrail will possibly become trapped in the ditch, causing instability problems and leading to severe and fatal accidents, as shown in Figure 2. The damage to the bus in the figure was caused partially by contact with the V-shaped ditch. This is particularly valid for the high center of gravity vehicles, such as busses.
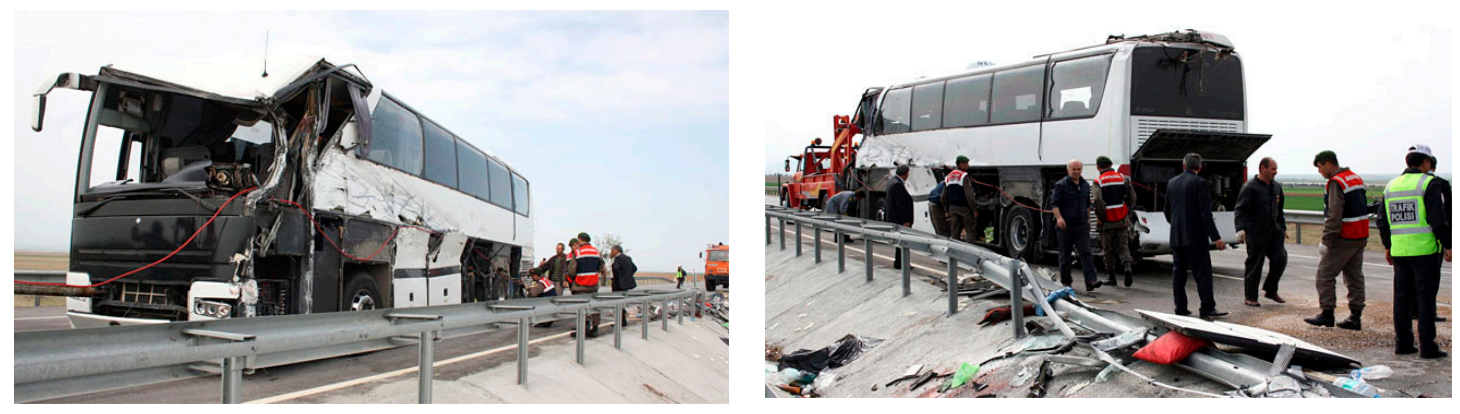

Figure 2. A bus accident at a V-shaped ditch protected with steel longitudinal barrier. 
This study aimed to evaluate the impact performance and effectiveness of steel and concrete longitudinal barrier designs used for long median sections. A three-dimensional finite element simulation program, LS-DYNA (LSTC, Livermore, CA, USA), was used to determine the adequacy of these two types of barriers when installed at a slope break point of a median ditch. The following sections explain the details of the study.

\section{Description of Barriers Studied}

\subsection{Concrete Barrier}

A new single-sided concrete barrier was developed for the purpose of improving traffic safety at medians. As shown in Figure 3, the concrete barrier is $3000 \mathrm{~mm}$ long, $470 \mathrm{~mm}$ wide, and $816 \mathrm{~mm}$ tall. Concrete barrier designs are based on the designers' past experiences and on the performances of similar barriers. Concrete blocks are connected to each other with three different mechanisms. Figure 4 illustrates central, lower, and back connectors. These connections are used to eliminate any possible separation and failure during vehicle impact, as well as provide a continuous and aesthetically pleasing wall. The compression strength of the concrete used in the barrier is $30 \mathrm{MPa}$ (C30). The impact strength of the concrete is improved with reinforcement bars used inside the blocks. Each block weighs approximately 2 tons, and two openings are formed under each block to alleviate handling and placement.

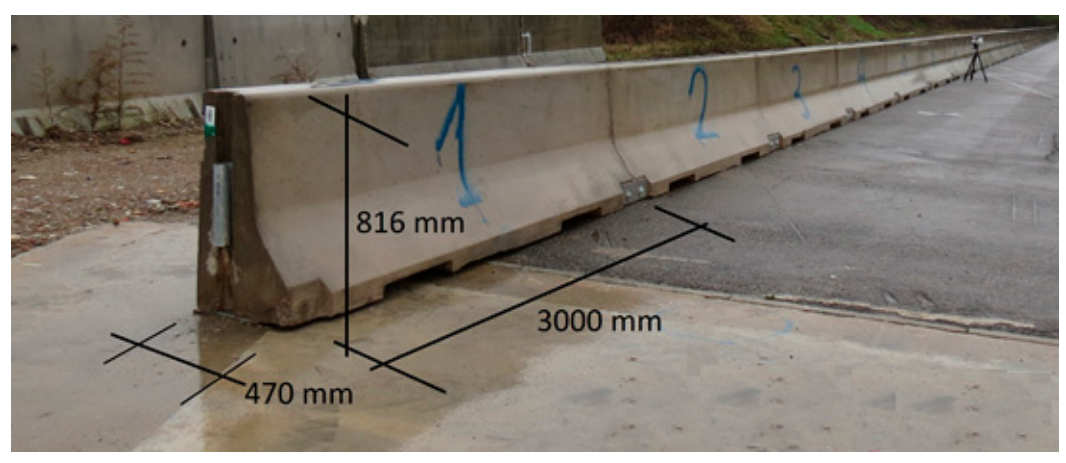

Figure 3. Dimensions of the single-sided concrete barrier.

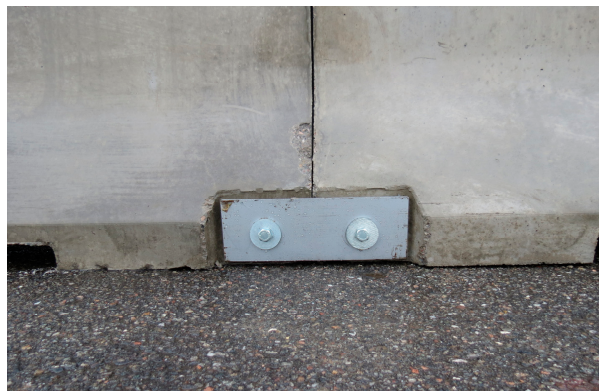

(a)

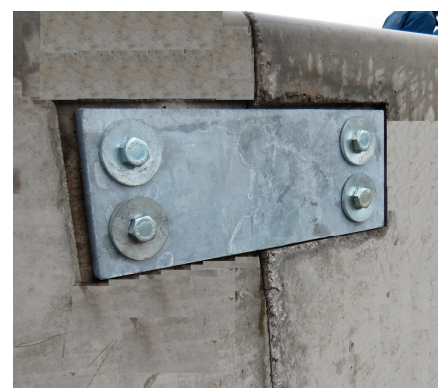

(b)

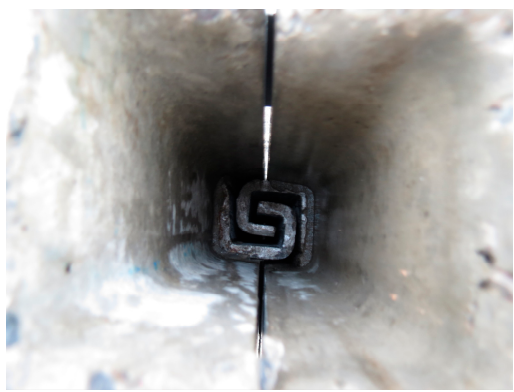

(c)

Figure 4. Concrete barrier connections: (a) lower, (b) rear, and (c) between blocks.

\subsection{Steel Barrier}

The majority of the guardrail systems used at ditches in Turkey are of an old German design, named EDSP-1.33 [10]. As shown in Figure 5, these steel barriers use five different components, including a $4.2 \mathrm{~mm}$ thick, $1900 \mathrm{~mm}$ long sigma-shaped post; a $3 \mathrm{~mm}$ thick W-beam; a $5 \mathrm{~mm}$ thick, $480 \mathrm{~mm}$ long spacer between the rail and the post; a $5 \mathrm{~mm}$ thick connector between the post and the spacer; and a $4 \mathrm{~mm}$ thick rear beam connecting the posts. All these parts are produced from S235 quality mild steel. Post spacing and post embedment depth in this design are $1330 \mathrm{~mm}$ and $1200 \mathrm{~mm}$, 
respectively. As shown in Figure 5, the top height of the design is $750 \mathrm{~mm}$. In most cases, as shown in Figures 2 and 5, the posts are installed inside or very close to the ditch slope break point due to the $500 \mathrm{~mm}$ length of the spacer and the short distance between the ditch and the roadway. A lack of adequate distance behind the barrier and the presence of a steep slope creates a safety risk for vehicles impacting the barrier and entering the slope.
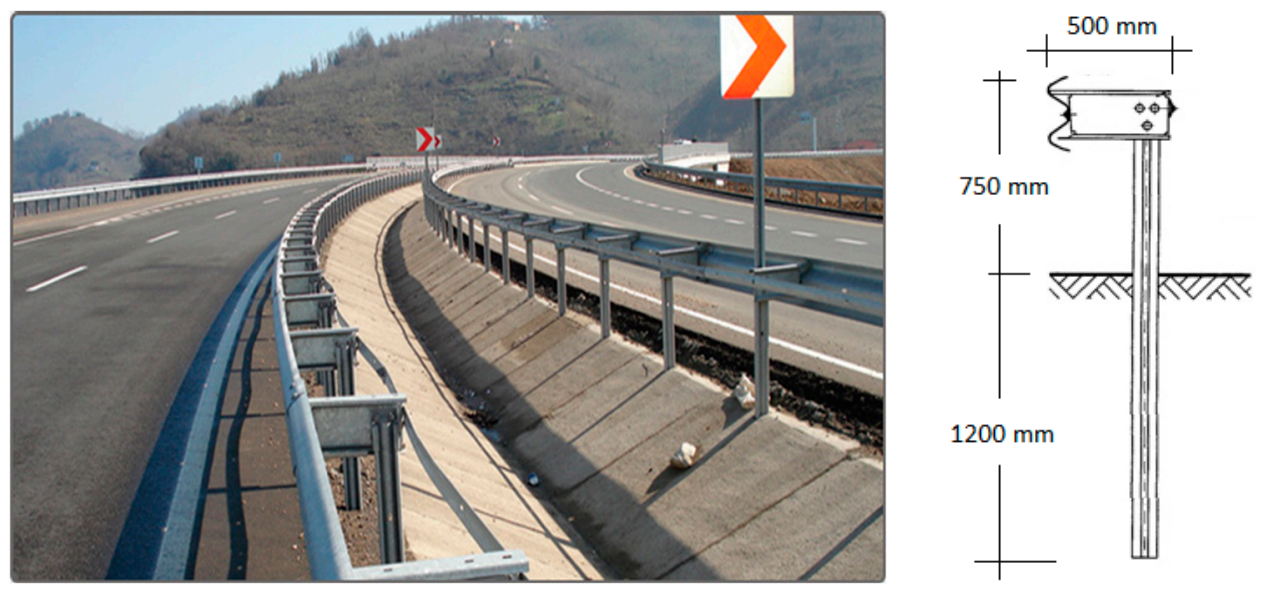

Figure 5. Dimensions and installed view of a steel barrier EDSP-1.33.

\section{Finite Element Simulation Study}

In this study, the crash performance of two different guardrails installed along the ditches was investigated using finite element analysis. Finite element models of the EDSP-1.33 steel barrier, currently in use, and a newly developed concrete barrier were constructed using the LS-DYNA program [11]. The finite element model of the concrete barrier was previously validated by full-scale crash tests [12]. The crash test simulations were performed using a $900 \mathrm{~kg}$ car (TB11) and a 10,000 kg truck (TB42). The finite element simulations successfully predicted the dynamic behavior of the concrete barrier, working width (W), injury risk criteria (ASI, THIV), and vehicle trajectories.

A bus model was used to impact the barriers in accordance with the European crash testing standard EN 1317 part 2. A bus was selected due to its higher center of gravity location and the presence of a large number of buses on divided highways in Turkey; therefore, the bus model allows for a better evaluation of the containment and redirection capacity of both barriers during a large-vehicle impact. Details of both barriers and the vehicle model are explained below.

\subsection{Description of Finite Element Models}

In order to investigate and analyze the crash performance of guardrails placed along a ditch, finite element models of steel and concrete barriers were created. A versatile, $3 \mathrm{D}$, large deformation finite element code, LS-DYNA, was utilized to perform the analysis. This was done in a manner consistent with the actual material behavior and geometry used for guardrails to accurately represent the guardrails used in practice.

A finite element model of the EDSP-1.33 was developed to assess the crash test performance of the design. The model, as shown in Figure 6, consisted of 104,321 nodes, 65,956 shell elements, and 17,407 solid elements. The shell elements represented the steel members of the model, while solid elements represented the ditch concrete. The shell elements of the W-beam and post that are expected to be in direct contact with an impacting vehicle and thus experience severe deformations were modeled with full integration formulation to accurately represent the complex interactions and behavior. All other steel elements were modeled with default element formulation for computational efficiency.

Since a barrier is expected to sustain large plastic deformations and possible crushing during vehicle impact, a piecewise linear plastic material definition was used to model the steel 
members $[13,14]$. Failure is included in the model to capture any potential rail ruptures. Rigid material modeling was used to represent the concrete surface of the ditch.

In an actual EDSP-1.33 installation, the connections between the members, such as a W-beam to a spacer and a post, are established using bolts and nuts. To accurately represent the behavior of these connections during simulation, the CONSTRAINED_SPOTWELD option in LS-DYNA was used [11]. By definition, this option keeps members connected until certain force criteria are met. Then, the connection fails, and members allow free movement. To accurately represent the crash behavior of the EDSP-1.33 design, this behavior is essential since the connections in the EDSP-1.33 barrier are designed to separate when forces reach a certain level. Therefore, a detailed connection model was constructed using LS-DYNA. The behavior of the connections was examined under different loading conditions. A reasonable failure criterion obtained from the component simulation was used in the connection model [14].

To model the concrete barrier, as shown in Figure 7, geometry and connection details of the barrier were developed and inputted into LS-DYNA. The model consisted of 82,645 nodes, 15,254 shell elements, and 57,203 solid elements. The shell elements represented the steel members, such as plate connectors and reinforcement of the model, while the solid elements represented the concrete and the ditch. As usual, the shell elements that are expected to undergo large deformations and stress concentrations were modeled with full integration formulation to accurately represent the complex interactions and behavior. All other steel elements were modeled with default element formulation and a piecewise linear plastic material definition. On the other hand, the concrete was modeled with a rigid material approximation since no failure is expected in concrete during a crash event.
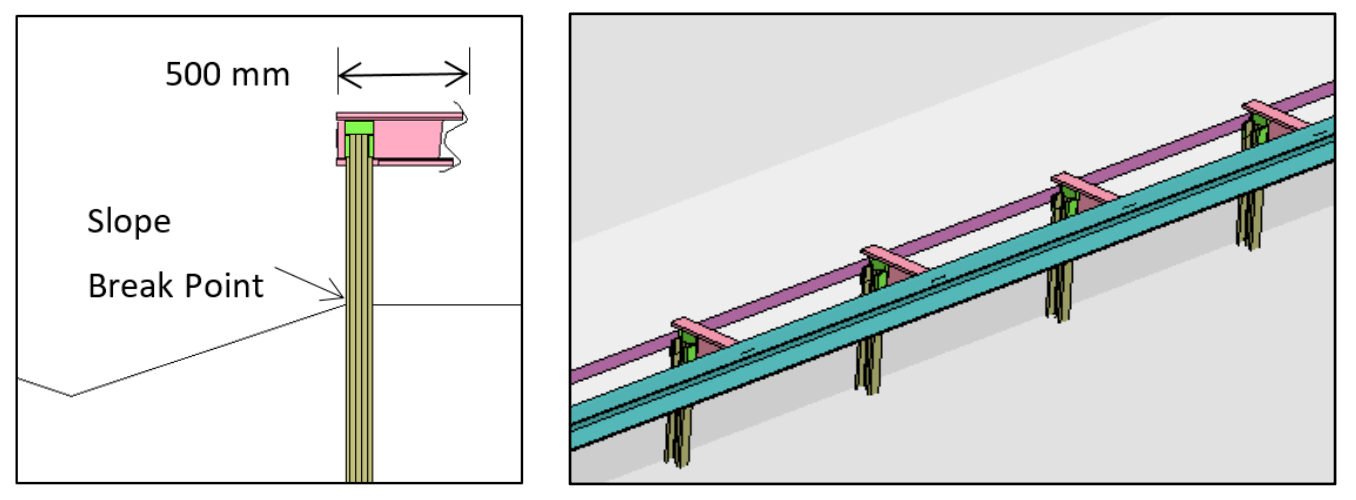

Figure 6. Finite element model of a steel EDSP-1.33 barrier installed at a slope break point of a ditch.
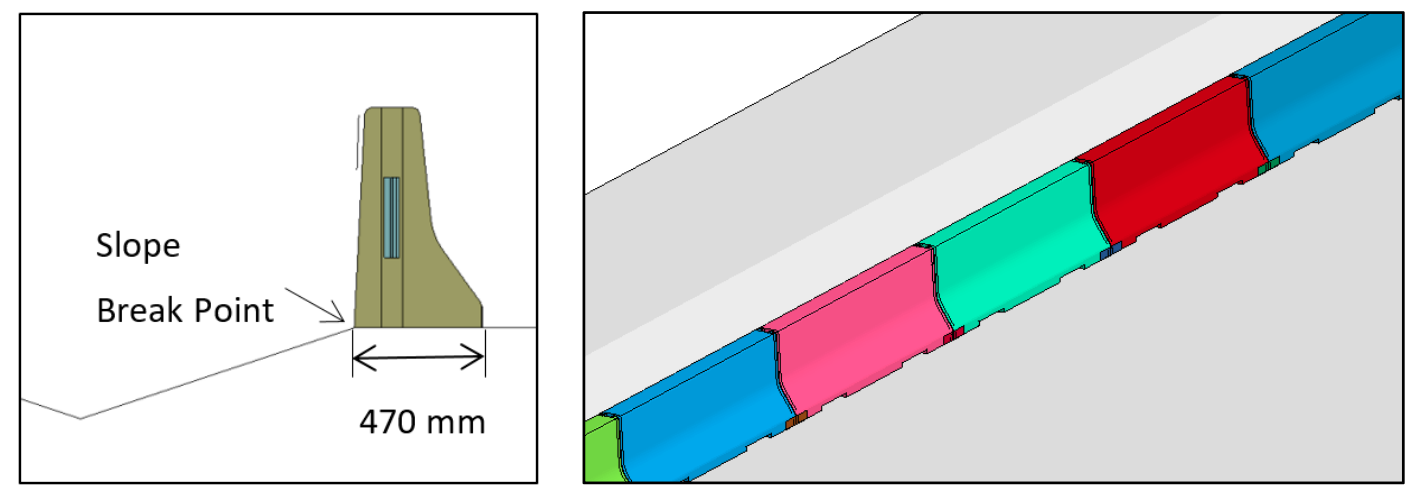

Figure 7. Finite element model of a concrete barrier installed at a slope break point of a ditch.

The 13,000 kg bus model used in the simulation is shown in Figure 8. This model was taken from a vehicle model library at the National Crash Analysis Center [15]. The accuracy of the bus model has been validated with actual tests. 


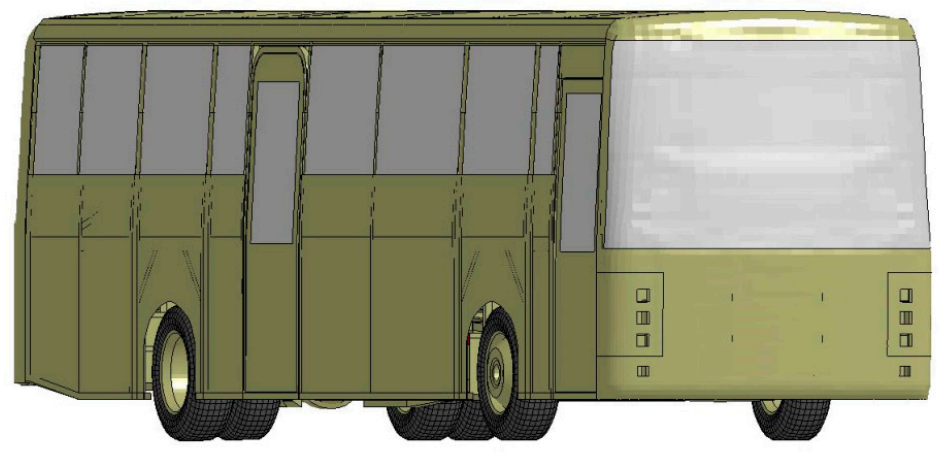

Figure 8. Finite element model of the $13,000 \mathrm{~kg}$ bus [NCAC, 2008].

Finally, a V-shaped ditch was modeled together with the road platform. Both the road section and ditch were modeled with rigid material since they are not expected to sustain any damages during simulations. Soil was modeled using the *SOIL_AND_FOAM material in LS-DYNA to accurately represent the post-soil interaction during an impact event. This model was successfully used in previous studies [16]. A ditch cross-section with steel and concrete barrier installations is shown in Figure 9.

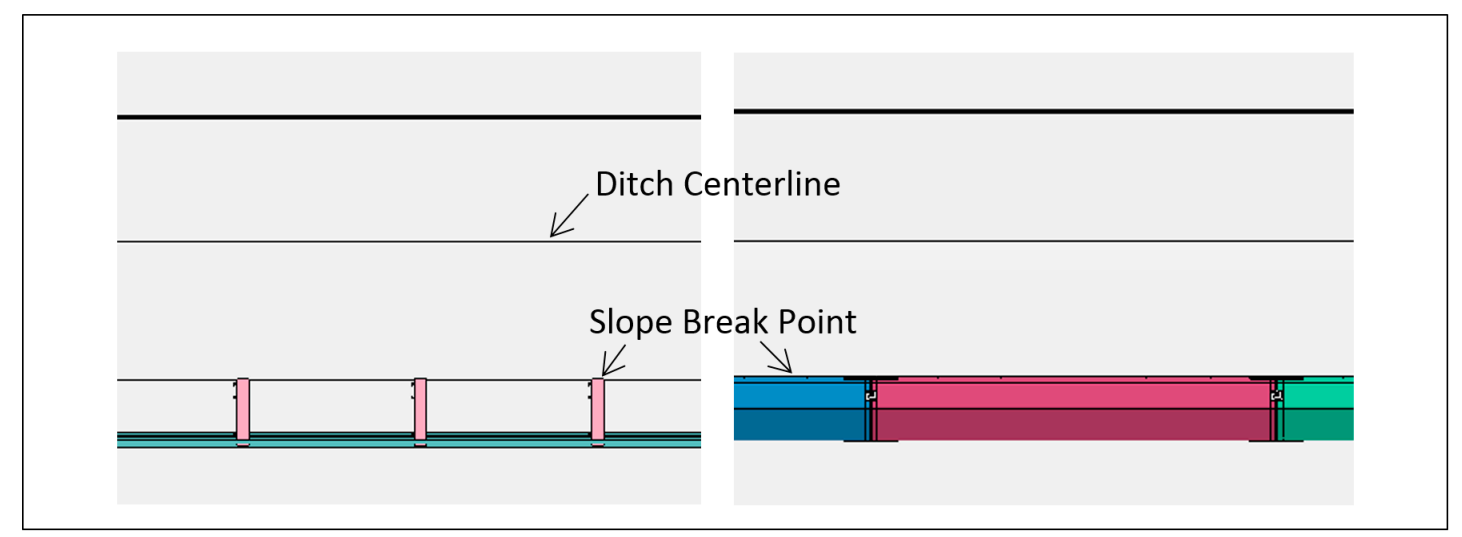

Figure 9. Finite element model of V-shaped ditch with both barrier models and the roadway (overhead view).

\subsection{EDSP-1.33 Steel Barrier Simulation Study}

After the final preparations on the bus model, the $13,000 \mathrm{~kg}$ bus was positioned in front of the barrier and impacted the barrier at $70 \mathrm{kph}$ and a 20-degree angle. These impact conditions were determined based on the recommendations set forth in EN 1317 Part 2 [8]. The kinetic energy of the bus just before impact was approximately $287 \mathrm{~kJ}$.

The simulation was run for about $1.0 \mathrm{~s}$ until the bus entered the ditch completely and became parallel with the barrier. As shown in Figures 10 and 11, when the vehicle hit the barrier, the W-rail and posts at the impact area began to deform. At $0.13 \mathrm{~s}$ after the initial impact, the spacer blocks started to separate from the posts, preventing the W-rail from moving downward with the posts. As the bus advanced forward, more posts were bent, and, at $0.3 \mathrm{~s}$ into the simulation, redirection of the bus became clear. The velocity of the vehicle at this point was approximately $62 \mathrm{kph}$. At $0.65 \mathrm{~s}$ after the initial contact with the barrier, the front section of the bus entered the ditch and almost reached the opposite side of the roadway. At this point, the damage to the EDSP-1.33 barrier was extensive, and the bus continued its forward movement. As shown in Figures 10 and 11, the bus became parallel with the barrier and ditch at around $0.95 \mathrm{~s}$, by which point more than half of the bus was already inside the ditch. Finally, around $1.0 \mathrm{~s}$ into the simulation, the bus began to exit the barrier in a stable manner. Based on the simulation predictions, it was determined that the EDSP-1.33 barrier is able 
to contain and redirect an impacting bus; however, the damage to the barrier was extensive and penetration of the ditch was significant. A picture of the deformed shape of the barrier is shown in Figures 12 and 13. The velocity of the bus upon exiting the barrier was $49 \mathrm{kph}$, representing a 30\% reduction in vehicle speed.

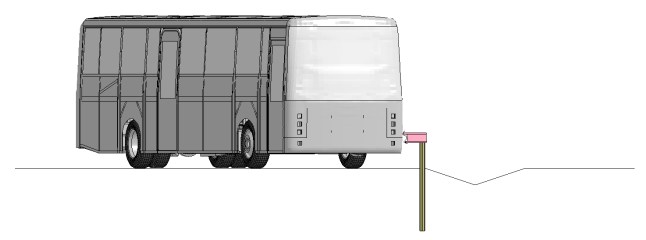

$0 \mathrm{~s}$
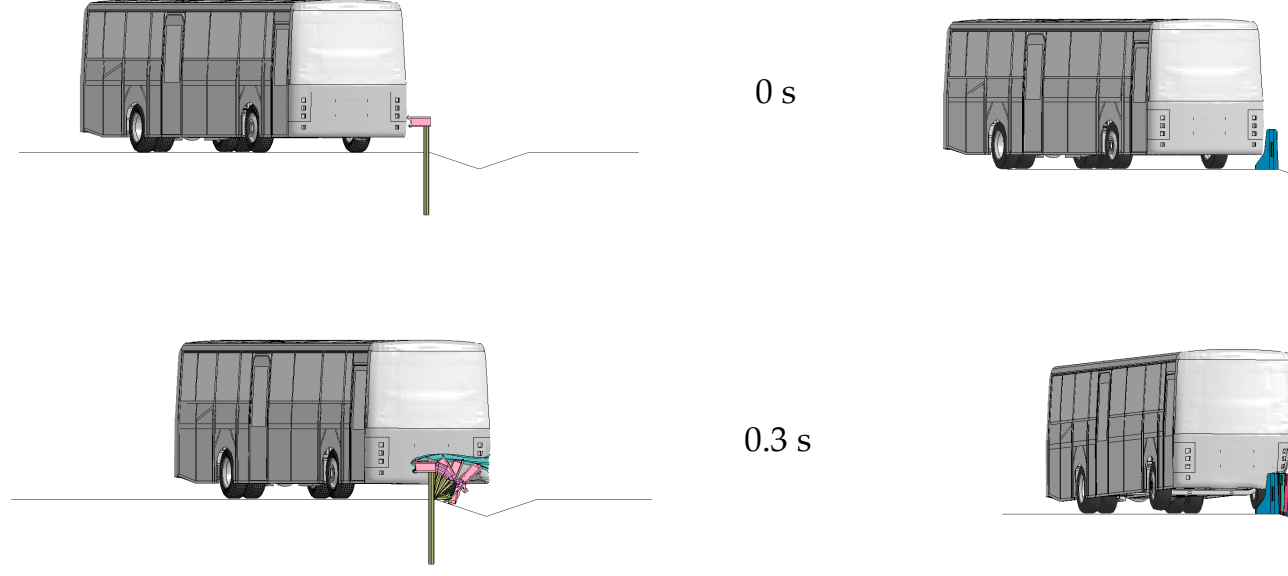

$0.3 \mathrm{~s}$
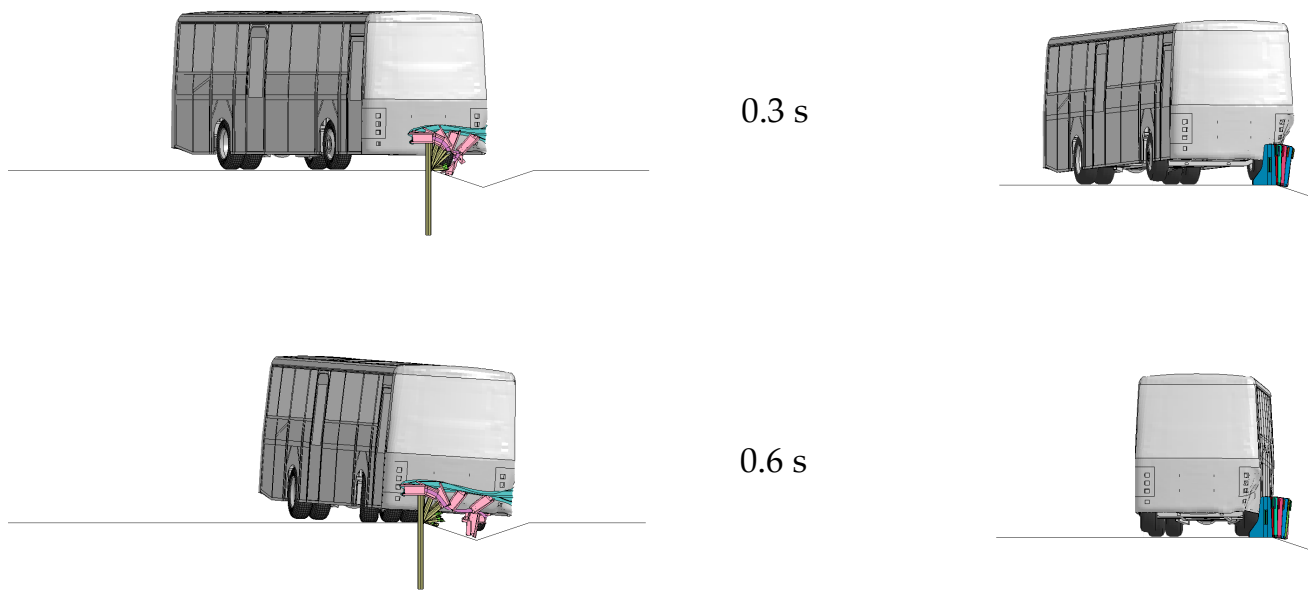

$0.6 \mathrm{~s}$
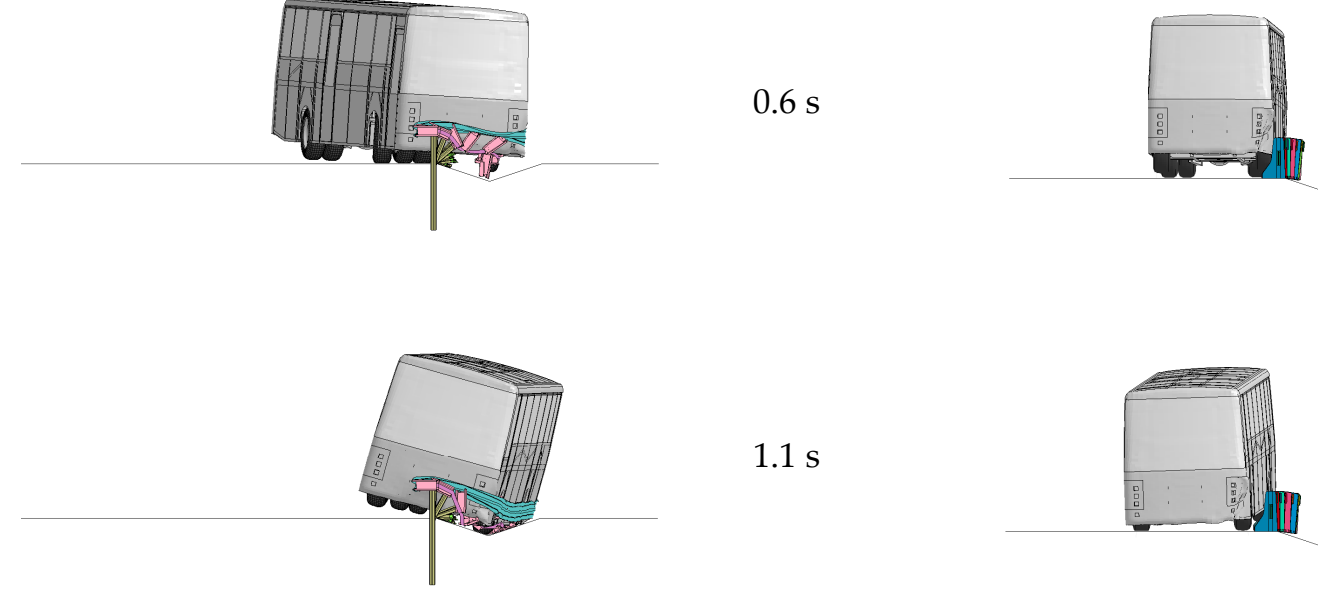

$1.1 \mathrm{~s}$

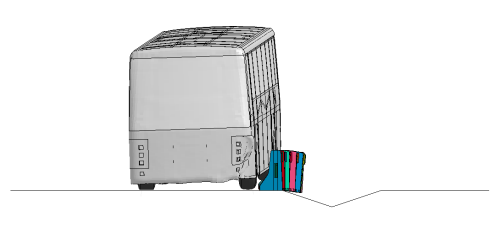

EDSP-1.33 Steel Barrier

C470 Concrete Barrier

Figure 10. Sequential front-view picture comparison of steel EDSP-1.33 and concrete C470 barriers after the bus impact simulation. 

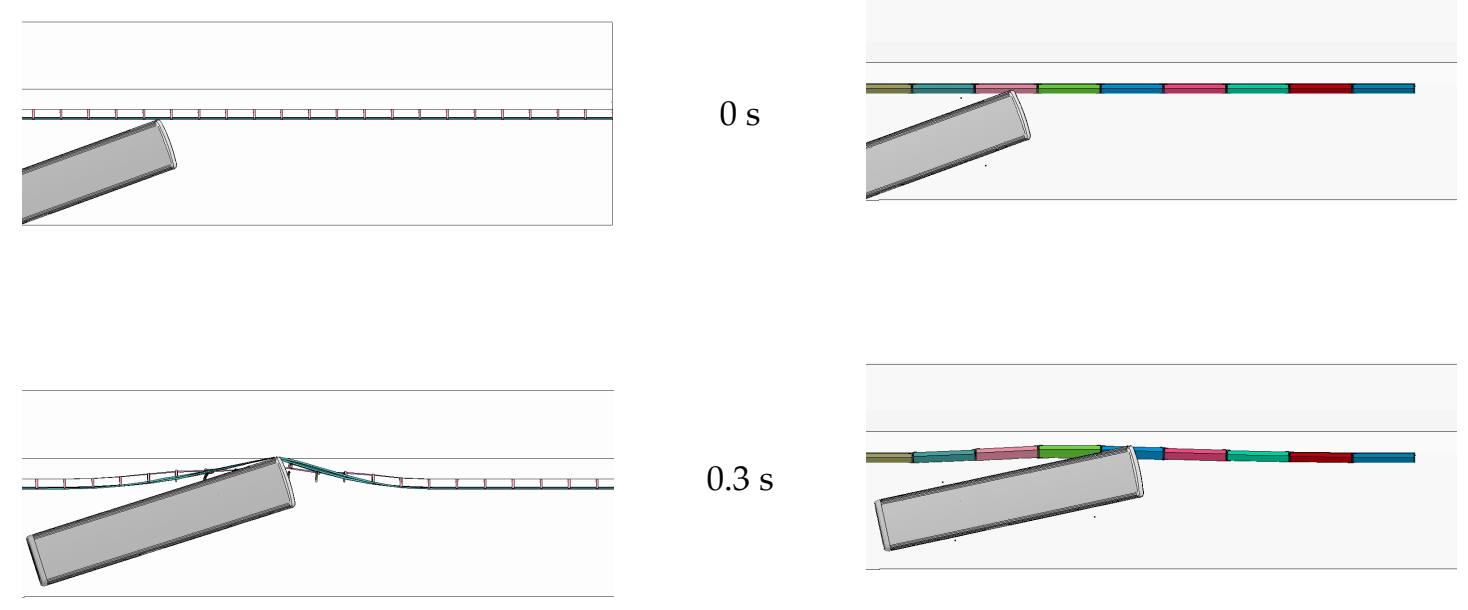

$0.3 \mathrm{~s}$
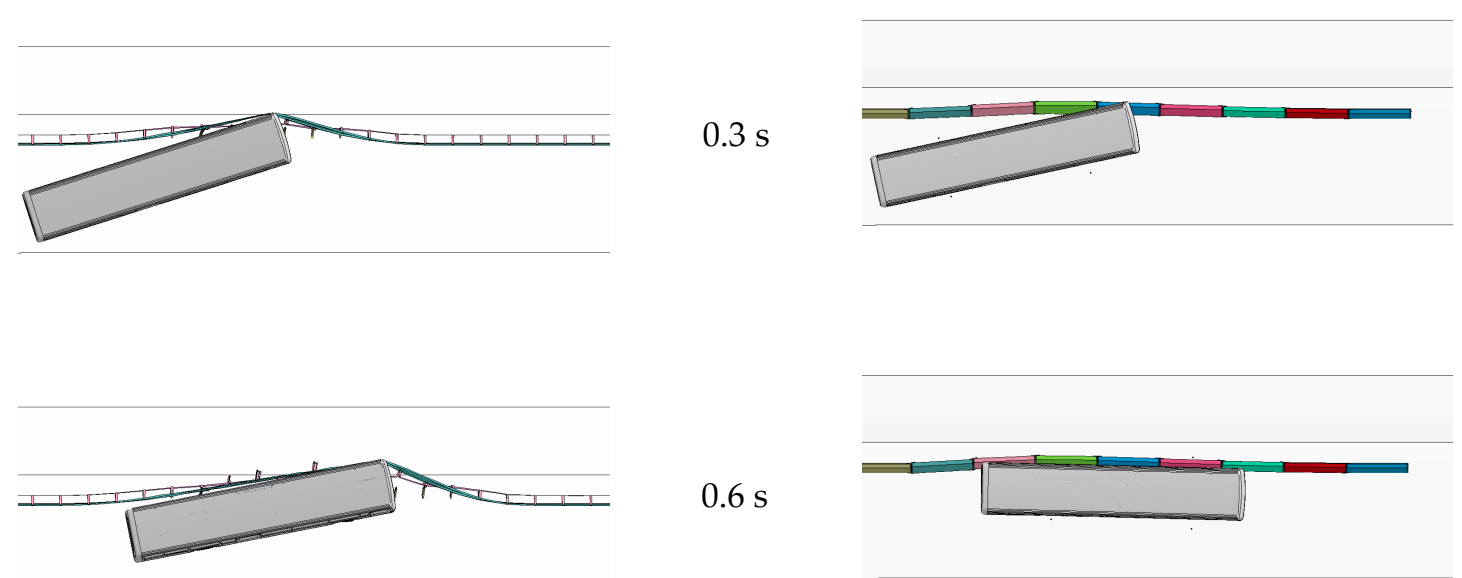

$0.6 \mathrm{~s}$
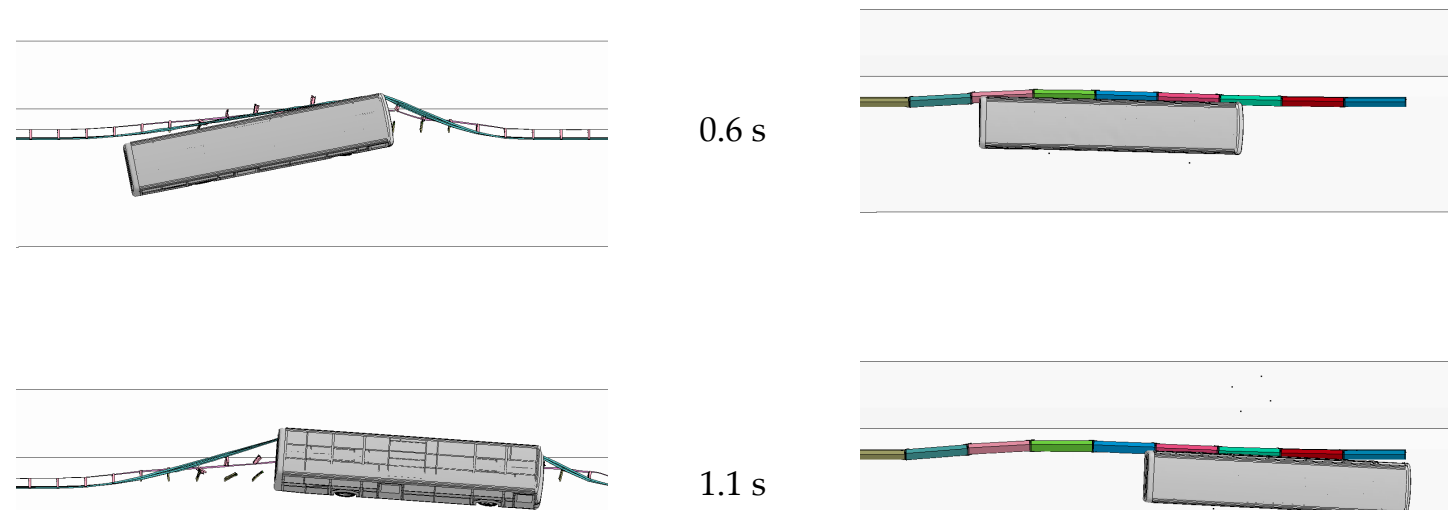

$1.1 \mathrm{~s}$

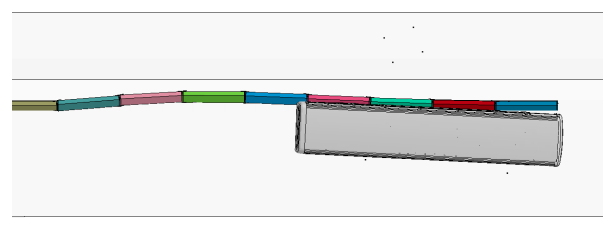

EDSP-1.33 Steel Barrier

C470 Concrete Barrier

Figure 11. Sequential overhead picture comparison of steel EDSP-1.33 and concrete C470 barriers after the bus impact simulation.

Ditch Centerline

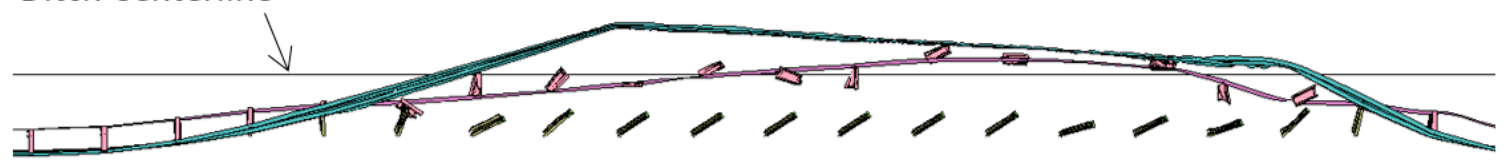

\section{Ditch Centerline}

Figure 12. Damage comparison for steel EDSP-1.33 and concrete C470 barriers after the bus impact simulation (overhead view). 
Deformation: $2200 \mathrm{~mm}$

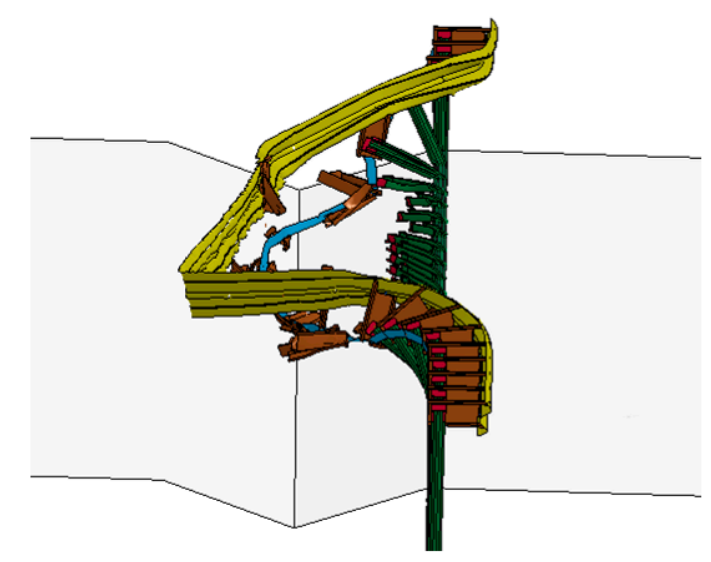

EDSP-1.33 Steel Barrier
Deformation: $960 \mathrm{~mm}$

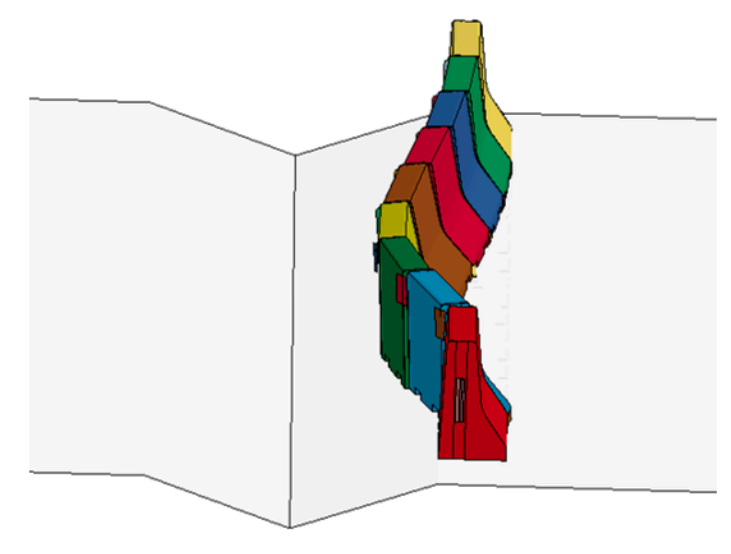

C470 Concrete Barrier

Figure 13. Comparison of damage to steel EDSP-1.33 and concrete C470 barriers after the bus impact simulation (front view).

\subsection{Concrete Barrier Simulation Study}

To run the impact simulation, as shown in Figures 10 and 11, the 13,000 kg bus model was positioned in front of the concrete barriers. Similar to the previous simulation, the bus impacted the barrier at 20 degrees and $70 \mathrm{kph}$ velocity. The bus contacted the connection section of the barrier, which represents the weakest section of the design. Soon after the initial contact, the barrier began to deform laterally and the impacting side of the front tire of the bus began to climb the barrier. At $0.15 \mathrm{~s}$ into the simulation, a total of three concrete blocks deformed laterally and, as they slid backward, they entered the ditch area. As shown in Figures 10 and 11, the bus began to change direction at $0.3 \mathrm{~s}$ and, at $0.58 \mathrm{~s}$, it became parallel with the concrete barrier and the ditch. At this point, the rear left tires impacted the already deformed barrier sections and pushed them further into the ditch. At $0.7 \mathrm{~s}$ into the simulation, one concrete block almost completely entered the ditch; however, due to strong connections between blocks, the concrete barrier remained upright and did not show any excessive deformation. Finally, at around $0.8 \mathrm{~s}$ into the simulation, the bus began to exit the concrete barrier. The velocity of the bus upon its exit was approximately $58 \mathrm{kph}$, and neither the bus nor the barrier showed any penetration of the ditch area. As shown in Figures 12 and 13, the damage to the concrete barrier was not significant, deformation was concentrated within a fairly small length, and the performance of the barrier was much improved compared to that observed from the steel EDSP-1.33 barrier. Based on the simulation results, it can be concluded that a well-connected and properly installed concrete barrier could be a potential alternative to the steel barriers used at median ditches.

The acceleration severity index (ASI) is used as a measure of the severity of an impact on the vehicle's occupants during a collision. The smaller the ASI index, the less severe the collision. As shown in Table 1, there are three severity classes specified in the EN 1317 standard: A, B, and C [8]. The ASI of the EDSP-1.33 steel barrier is class A, which means a low injury risk to the occupants [10]. During the full-scale crash tests, the ASI value for the C470 concrete barrier was measured as 1.55, which is class C [12]. Significant injuries occur when the ASI values are greater than 1.9 [8]. The ASI values both for the concrete C470 barrier and the steel EDSP-1.33 barrier are within the acceptable level with regard to injury risks. 
Table 1. Impact severity classes [8]. ASI: acceleration severity index.

\begin{tabular}{cc}
\hline Impact Severity Class & ASI \\
\hline A & $\leq 1$ \\
B & $\leq 1.4$ \\
C & $\leq 1.9$ \\
\hline
\end{tabular}

\section{Summary and Conclusions}

This paper aims to compare the impact performances of two different guardrail systems when they are used at a slope break point of ditches located at the median of divided highways. Crash test behaviors of both the steel EDSP-1.33 barrier and the concrete C470 barrier were predicted using nonlinear impact simulations. A highly reliable finite element program, LS-DYNA, was used for the analysis. Models for both barriers, a ditch, and a bus were prepared, and the crash simulation was performed in accordance with European standard requirements.

The simulation results show that when the steel EDSP-1.33 barrier is used, the bus has the potential for excessive penetration of the ditch, with a $2200 \mathrm{~mm}$ barrier deformation. Moreover, the barrier damage is extensive, resulting in increased maintenance costs. Previous crash tests performed on EDSP-1.33 showed that the occupant injury risks are within acceptable levels. On the other hand, the concrete $\mathrm{C} 470$ barrier successfully contains and redirects a $13,000 \mathrm{~kg}$ bus impact with minimal barrier deformation and low safety risk. Even though the concrete barrier slides toward the inside of the ditch by approximately $960 \mathrm{~mm}$, the bus does not enter the ditch area and exits the barrier in a stable manner. In agreement with results of a previous crash test on the C470 barrier, this test showed acceptable occupant injury risk values for this barrier.

To increase traffic safety, minimize maintenance costs, and improve the stability of heavy vehicles at ditches located at the median section of divided highways in Turkey, utilization of concrete barriers, particularly at curved section of roads, is strongly recommended. It should be noted that utilization of EDSP-1.33 could be considered at median locations where a large working width is not a concern.

Author Contributions: In the preparation of this article Atahan was responsible from concept development and finite element analysis, Arslan was from making decisions on barrier selection, Sevim was from material selection and performance verification and finally Res. Yücel was responsible from LS-DYNA analysis and structuring the paper.

Funding: This research was partially funded by TUBITAK Grant Number 110M235.

Acknowledgments: Support by Istanbul Metropolitan Municipality and Turkish Roads Association is gratefully acknowledged.

Conflicts of Interest: The authors declare no conflict of interest.

\section{References}

1. Chitturi, M.V.; Ooms, A.W.; Bill, A.R.; Noyce, D.A. Injury outcomes and costs for cross-median and median barrier crashes. J. Saf. Res. 2011, 42, 87-92. [CrossRef] [PubMed]

2. AASHTO. A Policy on Geometric Design of Highways and Streets; American Association of State Highway and Transportation Officials: Washington, DC, USA, 2004.

3. Noyce, D.A.; McKendry, R.J. Analysis of Median Crossover Crashes in Wisconsin; University of Wisconsin Traffic Operations and Safety Laboratory: Madison, WI, USA, 2005.

4. Qin, X.; Wang, F.; Bill, A.R.; Chitturi, M.V.; Noyce, D.A. Evaluation of High Tension Cable Barriers in Wisconsin; Report No. FEP-04-09; University of Wisconsin-Madison: Madison, WI, USA, 2010.

5. Martin, J.L.; Mintsa-Rya, C.; Goubel, C. Long-term analysis of the impact of longitudinal barriers on motorway safety. Accid. Anal. Prev. 2012, 59, 443-451. [CrossRef] [PubMed]

6. Ray, M.H.; Silvestri, C.; Conron, C. Experience with Cable Median Barriers in United States: Design Standards, Policies and Performance. J. Transp. 2009, 153, 711-720. [CrossRef] 
7. Atahan, A.O.; Bonin, G.; Cicinnati, L.; Yasarer, H. Development of European end treatment TWINY using simulation and crash testing. J. Transp. Eng. 2008, 134, 467-476. [CrossRef]

8. CEN. EN1317-2, Road Restraint Systems_Part 2: Performance Classes, Impact Test Acceptance Criteria and Test Methods for Safety Barriers; European Committee for Standardization: Brussels, Belgium, 2010.

9. Yucel, A.O. Evaluation of Effects of Median Ditches on the Vehicle Stability Using Dynamic Analysis. Master's Thesis, Mustafa Kemal University, Hatay, Turkey, 2010.

10. RAL. International Standard for Evaluation of Steel for Road Safety Systems. 1990. Available online: http:/ / www.guetegemeinschaft-stahlschutzplanken.de/index.php?option=com_content\&view= article\&id=6\&Itemid=7 (accessed on 28 October 2018).

11. LSTC. LS-DYNA User's Manual; Livermore Software Technology Corporation: Livermore, CA, USA, 2012.

12. Atahan, A.O.; Büyük, M.; Çağlı, S.; Bayraktar, M.E. Design, Analysis and Crash Test of a Domestic Concrete Barrier in accordance with CE Standards (in Turkish). In Proceedings of the Transist 2017 International Istanbul Transport Congress and Exhibition, Istanbul, Turkey, 2-4 November 2017; pp. 514-524.

13. Vesenjak, M.; Borovinsek, M.; Ren, Z. Computational and experimental crash analysis of the road safety. Eng. Fail. Anal. 2005, 12, 963-973.

14. Atahan, A.O.; Bonin, G. Numerical analysis of an H4a heavy containment level transition. Int. J. Heavy Veh. Syst. 2006, 13, 351-365. [CrossRef]

15. NCAC. National Crash Analysis Center, George Washington University. Available online: http:/ / www.ncac. gwu.edu/vml/models.html (accessed on 15 December 2010).

16. Atahan, A.O.; Yucel, A.O.; Guven, O. Risks of Unprotected Median Drainage Ditches on Vehicle Stability. In Proceedings of the Roadside Safety Design and Devices, Milan, Italy, 17 July 2012; pp. 135-142.

(C) 2018 by the authors. Licensee MDPI, Basel, Switzerland. This article is an open access article distributed under the terms and conditions of the Creative Commons Attribution (CC BY) license (http:/ / creativecommons.org/licenses/by/4.0/). 